\title{
Mandatory use of confirmation stage with Chlamydiazyme during urinary sediment analysis
}

\author{
J R Anderson, G Mumtaz, P Mulhare, J Poddar, G L Ridgway
}

\begin{abstract}
Aims-To assess whether false positive results found when the first stage Chlamydiazyme test is performed on urinary sediment could be reduced by using the more specific second stage blocking assay.

Methods-Sediment from 173 urine samples from patients with suspected urinary tract infection caused by Gram negative bacteria and 23 control urine samples were tested using the Chlamydiazyme assay system, which included a blocking assay.
\end{abstract}

Results-A reaction result with the first stage Chlamydiazyme assay test was seen in $102(58.9 \%)$ of the test urine samples. First stage reactivity was not blocked by the Chlamydiazyme confirmatory assay performed on repeat testing. All were correctly identified as true negative (first test false positive) results.

Conclusions-Use of a second (specific) blocking assay for the analysis of urinary sediment using Chlamydiazyme eliminates false positive results in Gram negative urinary tract infections.

(F Clin Pathol 1993;46:896-897)

A variety of enzyme immunoassays (EIA) have become available for the diagnosis of Chlamydia trachomatis infections in clinical specimens. EIAs vary in specificity and sensitivity depending on the site from which the specimen is taken, and the prevalence of $C$ trachomatis in the clinic from which samples are received. They remain attractive techniques because they are fast, ideally suited to processing large numbers of specimens, and amenable to automisation. One recurrent problem in the use of EIAs for the diagnosis of chlamydial infections has been that a wide variety of organisms (both Gram positive and Gram negative bacteria and viruses) may produce false positive results. ${ }^{1-4}$ This has special relevance to urinary sediment analysis as many organisms capable of causing false positive EIA results may also give rise to urinary tract infections. A recently published paper suggested that the Chlamydiazyme system (Abbott Diagnostic Laboratories, Chicago, USA) was unsuitable for diagnosing $C$ trachomatis infection by urinary sediment analysis as the false positive result rate was unacceptably high in the presence of such organisms. ${ }^{5}$ This study, however, did not use the second highly specific confirmatory test to attempt verification of results. ${ }^{4}$ We therefore decided to assess whether the false positive results found when the first stage Chlamydiazyme test is performed on urinary sediment could be reduced by using the more specific second stage blocking assay.

\section{Methods}

Test urine sediments $(n=173)$ were selected from urine samples sent to our laboratory for the investigation of possible urinary tract infection. A growth of greater than $10^{4}$ organisms $/ \mathrm{ml}$ of a probable Gram negative organism was required for a urine sample to be eligible for the study. Organism identification was confirmed using normal laboratory methods $^{6}$ on the same day that the Chlamydiazyme assay was being run, and subsequently noted. Control urine samples were selected at random from those sent to our laboratory for pregnancy testing but with no history of urinary symptoms. A sample of each control urine sample was plated on to cysteine lactose electrolyte deficient agar (CLED; Oxoid) to check for bacterial contamination or undiagnosed urinary tract infection.

A 5-10 $\mathrm{ml}$ aliquot (depending on the initial volume available) of each urine sample was centrifuged at $3000 \mathrm{rpm}$ for 15 minutes and the supernatant fluid discarded. The pellet was stored at $4^{\circ} \mathrm{C}$ for not more than 18 hours until the Chlamydiazyme first stage test was performed. The pellet was resuspended in 1 $\mathrm{ml}$ of phosphate buffered saline and an aliquot of suspension processed according to the manufacturer's instruction. Incubations were performed in a Commander dynamic incubator (Abbott Diagnostic Laboratories); washings and colour reading were performed automatically using a Commander parallel processing centre (Abbott Diagnostic Laboratories).

If a pellet was found to give a positive or equivocal result with the first stage test, a further aliquot of suspension was processed for the confirmatory test according to the manufacturer's instructions.

\section{Results}

Test urine samples were found to give reactive results in 102 of $173(58.9 \%)$ cases with the first stage Chlamydiazyme test. First stage reactivity was not blocked by the confirmatory test for any of the urine samples tested, 
Range of organisms isolated from urinary sediments (test urines only) showing significant bacteriuria and their reactivity with first and second stage Chlamydiazyme tests

\begin{tabular}{|c|c|c|c|c|}
\hline $\begin{array}{l}\text { Identified } \\
\text { organism }\end{array}$ & $\begin{array}{l}\text { Total No } \\
\text { of isolates }\end{array}$ & $\begin{array}{l}\text { No of isolates } \\
\text { showing first stage } \\
\text { reactivity }\end{array}$ & $\begin{array}{l}\text { \% isolates } \\
\text { showing first stage } \\
\text { reactivity }\end{array}$ & $\begin{array}{l}\text { \% first stage } \\
\text { reactive isolates } \\
\text { blocked with } \\
\text { confirmatory test }\end{array}$ \\
\hline$E$ coli & 123 & 76 & 62 & 0 \\
\hline Klebsiella spp & 11 & 11 & 100 & 0 \\
\hline Proteus spp & 9 & 4 & 44 & 0 \\
\hline Enterobacter spp & 13 & 4 & 31 & 0 \\
\hline Serratia sp & 7 & 4 & 57 & 0 \\
\hline $\mathrm{MDS}^{\star}$ & 1 & 1 & 100 & 0 \\
\hline Citrobacter & 3 & 1 & 33 & 0 \\
\hline Xanthomonas sp & 1 & 1 & 100 & 0 \\
\hline Providencia sp & i & 0 & 0 & \\
\hline Acinetobacter sp & 1 & 0 & 0 & \\
\hline Enterococcus sp & 1 & 0 & 0 & \\
\hline Candida sp & 1 & 0 & 0 & \\
\hline
\end{tabular}

${ }^{\star}$ Mixed growth of doubtful importance-that is, $>10^{4}$ organisms $/ \mathrm{ml}$ and $>$ two colonial types.

hence all were ultimately recognised as true negative results.

Control urine samples gave reactive results in two of $23(6.9 \%)$ cases. The two with reactive results were both from urine samples submitted to the laboratory for pregnancy testing. One yielded more than $10^{5}$ Escherichia coli $/ \mathrm{ml}$ and the other showed a profuse mixed growth of doubtful clinical relevance. In both cases the confirmatory Chlamydiazyme test failed to block colour production, hence both were recognised as true negative results.

The organisms isolated from culture positive urine samples, together with the preliminary and confirmatory Chlamydiazyme test results are shown in the table. Two urine samples yielded a heavy growth of two Gram negative organisms. Neither of these were reactive on preliminary Chlamydiazyme testing. Three urine samples (including one of the control urine samples showing bacterial growth) showed a heavy mixed growth of doubtful clinical important. One of these was reactive on preliminary testing but was not blocked with the second assay. The percentage of isolates producing first stage reactivity with the Chlamydiazyme assay varied between 0 and $100 \%$, depending on the identity of the organism.

Organisms isolated included $E$ coli, Klebsiella sp, Pseudomonas sp, Proteus sp, Enterobacter sp, Serratia sp, Xanthomonas sp, and Aeromonas sp. The percentages of organisms giving a reactive preliminary Chlamydiazyme test are shown in the table.

There was no relation between urine volume centrifuged and enzyme linked immunosorbent assay (ELISA) value within the range of urine volumes tested $(5-10 \mathrm{ml})$.

\section{Discussion}

Our results for Chlamydiazyme first stage reactivity agree with previous results obtained on urinary sediments. ${ }^{5-7}$ Specificity for the Chlamydiazyme preliminary test was calculated as $41 \%$ (71 of 173). In contrast to
Demai et $a l,,^{5}$ we also used the confirmatory Chlamydiazyme test. The confirmatory test was introduced to improve the specificity of the original Chlamydiazyme test, ${ }^{4}$ and uses a murine monoclonal antibody directed against $C$ trachomatis lipopolysaccharides. The use of the confirmatory test eliminated false positive reactions caused by urinary bacteria. This is important if urine samples are to be used as a screening procedure in male patients.

If urinary sediment testing were to become a routine diagnostic test (for male patients attending STD clinics, for instance), then any first stage reactive results using the Chlamydiazyme test could easily be checked using the confirmatory test as part of routine laboratory procedure. It should be appreciated that in practice the number of patients with urinary tract infections would be low and the percentage of samples in which bacterial growth was sufficient to produce false positive results would be even lower. Provided the confirmatory test is used, the specificity of the Chlamydiazyme system is satisfactory for testing urine sediments for the presence of $C$ trachomatis.

The choice of technique(s) and kits for diagnosis of $C$ trachomatis in routine samples also has financial implications. Culture is slow, labour intensive, and expensive. Immunofluorescence is less slow but is still labour intensive and relatively expensive. Neither of these techniques is especially suitable for first screening large numbers of specimens. Testing with EIA is likely to remain the "first line" screening method for diagnostic centres and the choice of a suitable kit is of fundamental importance. It is clear from our results that if urine sediments are to be assayed using Chlamydiazyme then the second stage test is mandatory, as the risk of a false positive result is much too high if only the first stage test is used.

1 Riordan T, Ellis DA, Matthews PI, Ratcliffe SF. False positive results with an enzyme linked immunosorbant positive results with an enzyme linked immunosorbant assay for detectio

2 Taylor-Robinson D, Thomas BJ, Osborne MF. Evaluation of enzyme immunoassay (Chlamydiazyme) for detecting Chlamydia trachomatis in genital tract specimens. f Clin Pathol 1987;40:194-9.

3 Hammerschlag MR, Retting PJ, Shields ME. False positive results with the use of chlamydial antigen detection tests in the evaluation of suspected sexual abuse in children. Paediatr Infect Dis 1988;7:11-4.

4 Moncada J, Schachter J, Bolan G, et al. Confirmatory assay increases the specificity of the Chlamydiazyme test for Chlamydia trachomatis infections of the cervix. $₹$ Clin for Chlamydia trachomatis inf

5 Demaio J, Boyd RS, Rensi R, Clark A. False-positive Chlamydiazyme results during urine sediment analysis due to bacterial urinary tract infections. $\mathcal{F}$ Clin Microbiol 1991;29:1436-8.

6 Stokes EJ, Ridgway GL. In: Clinical Microbiology. 6th Edn. London: Edward Arnold, 1987:37-41, 85-142

7 Mumtaz G, Ridgway GL, Clark S, Allason-Jones E. Evaluation of an enzyme immunoassay (Chlamydiazyme) with confirmatory test for the detection of chlamydial antigen in urine from men. Int $\mathcal{F}$ STD AIDS $1991 ; 2: 359-61$. 